OPEN ACCESS

Edited by:

Guangchun Bai,

Albany Medical College, USA

Reviewed by:

Lesley McGee,

Centers for Disease Control and

Prevention, USA

Werner Albrich

Kantonsspital St. Gallen, Switzerland

Lucia Martins Teixeira

Federal University of Rio de Janeiro,

Brazil

*Correspondence: David S. Stephens dstep01@emory.edu

Received: 12 May 2016 Accepted: 26 August 2016 Published: 21 September 2016

Citation:

Schroeder MR and Stephens DS (2016) Macrolide Resistance in

Streptococcus pneumoniae.

Front. Cell. Infect. Microbiol. 6:98. doi: $10.3389 / f c i m b .2016 .00098$

\section{Macrolide Resistance in Streptococcus pneumoniae}

\author{
Max R. Schroeder ${ }^{1}$ and David S. Stephens 1,2,3* $^{2}$ \\ ${ }^{1}$ Departments of Medicine, Emory University, Atlanta, GA, USA, ${ }^{2}$ Departments of Microbiology and Immunology, Emory \\ University, Atlanta, GA, USA, ${ }^{3}$ Departments of Epidemiology, Emory University, Atlanta, GA, USA
}

Streptococcus pneumoniae is a common commensal and an opportunistic pathogen. Suspected pneumococcal upper respiratory infections and pneumonia are often treated with macrolide antibiotics. Macrolides are bacteriostatic antibiotics and inhibit protein synthesis by binding to the $50 S$ ribosomal subunit. The widespread use of macrolides is associated with increased macrolide resistance in $S$. pneumoniae, and the treatment of pneumococcal infections with macrolides may be associated with clinical failures. In S. pneumoniae, macrolide resistance is due to ribosomal dimethylation by an enzyme encoded by erm(B), efflux by a two-component efflux pump encoded by $m e f(E) / m e /(m s r(D))$ and, less commonly, mutations of the ribosomal target site of macrolides. A wide array of genetic elements have emerged that facilitate macrolide resistance in S. pneumoniae; for example erm(B) is found on Tn917, while the mef(E)/mel operon is carried on the $5.4-$ or $5.5-\mathrm{kb}$ Mega element. The macrolide resistance determinants, erm(B) and mef(E)/mel, are also found on large composite Tn916-like elements most notably Tn6002, Tn2009, and Tn2010. Introductions of 7-valent and 13-valent pneumococcal conjugate vaccines (PCV-7 and PCV-13) have decreased the incidence of macrolide-resistant invasive pneumococcal disease, but serotype replacement and emergence of macrolide resistance remain an important concern.

Keywords: Streptococcus pneumoniae, antibiotic resistance, macrolide resistance, erm(B), mef(A/E)/mel(msr(D)), Mega, pneumococci

\section{INTRODUCTION}

Streptococcus pneumoniae, the pneumococcus, is a commensal of the human nasopharynx and an opportunistic pathogen that is a leading worldwide cause of death for children under the age of 5 years (Walker et al., 2013). In addition to localized infections such as otitis media and pneumonia, the pneumococcus may cause severe invasive disease (IPD) including bacteremia and meningitis. Development of penicillin resistance in the pneumococcus in the 1980s-1990s shifted antibiotic treatment of suspected pneumococcal upper respiratory infections and pneumonia to macrolides. Widespread macrolide use, however, is associated with increased macrolide resistance in S. pneumoniae (Bergman et al., 2006; Malhotra-Kumar et al., 2007). Clinical failures of macrolide treatment of pneumococcal infections have been reported for lower respiratory tract infections (Klugman, 2002) and bacteremia (Lonks et al., 2002; Schentag et al., 2007). Widespread macrolide use is a strong selective pressure contributing to the expansion of macrolide-resistant S. pneumoniae (Bergman et al., 2006; Keenan et al., 2015). Globally, macrolide resistance among S. pneumoniae is geographically variable but ranges from $<10 \%$ to $>90 \%$ of isolates (Farrell et al., 2008; Pan et al., 2015; Xiao et al., 2015). 


\section{MACROLIDE ANTIBIOTICS}

Macrolides are defined by a complex macrocyclic structure with a 14-, 15-, or 16-membered lactone ring substituted with neutral or amino sugar groups. Macrolides inhibit bacterial protein synthesis by binding to the large $50 \mathrm{~S}$ ribosomal subunit and disrupting protein elongation by causing the dissociation of the peptidyl-tRNA.

Erythromycin, discovered in 1952, is a 14-membered macrolide produced by Saccharopolyspora erythraeus (formerly Streptomyces erythraeus; McGuire et al., 1952). After the discovery of erythromycin and other naturally-produced macrolides, research focused on the creation of synthetic and semisynthetic macrolides (Kirst, 2010; Seiple et al., 2016). Azithromycin and clarithromycin are semisynthetic macrolides approved for use in the United States, and azithromycin is one of the most prescribed antibiotics in the US (Hicks et al., 2015). Additional macrolides such as roxithromycin and josamycin are approved in other countries worldwide. Macrolides bind reversibly to the $23 \mathrm{~S}$ rRNA at a site near the peptidyl transferase center of the 50S ribosomal subunit (Kannan and Mankin, 2011). Macrolide binding occurs in pre-structured ribosomal assemblies (Pokkunuri and Champney, 2007). The smaller macrolides (14and 15-membered) partially block the nascent peptide channel to inhibit the elongating peptide chain while larger macrolides (16-membered) fully block the nascent peptide channel and cause ribosomal disassociation that reversibly inhibits protein synthesis (Weisblum, 1995b). Though distinct in chemical structure, the lincosamide and streptogramin class antibiotics have overlapping binding sites with macrolides and have similar mechanisms of action (Kirst, 2010).

\section{MECHANISMS OF MACROLIDE RESISTANCE}

\section{Ribosomal Modification}

Erythromycin ribosomal methylase (erm) family genes encode adenine-specific $\mathrm{N}$-methyltransferases that methylate the $23 \mathrm{~S}$ rRNA to prevent antibiotic binding (Weisblum, 1995a). The ribosomal methylase found in $S$. pneumoniae is primarily encoded by $\operatorname{erm}(\mathrm{B})$ whose gene product dimethylates the target site of the 23S rRNA (A2058 in Escherichia coli; Skinner et al., 1983; Johnston et al., 1998). The erm (B) gene is the most common macrolide resistance determinant in S. pneumoniae (Table 1). Erm(A) subclasses erm(A) (Syrogiannopoulos et al., 2001) and erm(TR) (Camilli et al., 2008) are rarely found in S. pneumoniae. Ribosomal methylation by $\operatorname{Erm}(\mathrm{B})$ confers resistance to macrolides, lincosamides, and streptogramin $\mathrm{B}$, which is characterized as the $\mathrm{MLS}_{\mathrm{B}}$ phenotype (Weisblum, 1995a). In addition to the expanded spectrum of resistance, erm (B) provides high-level resistance to macrolides (erythromycin MICs usually $\geq 256 \mu \mathrm{g} / \mathrm{ml}$ ).

The induction of $\operatorname{erm}(\mathrm{B})$ allows high-level translation of $\operatorname{Erm}(\mathrm{B})$ in the presence of inducers such as erythromycin (Chancey et al., 2011). In the pneumococcus, erm(B) expression may be inducible or constitutively expressed to high levels. As expression of erm genes is repressed in the absence of inducing drugs through a mechanism of translational attenuation; erm(B) expression has been proposed to have a bacterial fitness cost (Min et al., 2008; Chancey et al., 2012; Gupta et al., 2013). A recent study found that a Staphylococcus aureus strain expressing erm (C) was outcompeted by $S$. aureus expressing catalyticallyinactive erm(C) (Gupta et al., 2013), supporting the need for tight regulation of expression. Interestingly, deletion of the leader sequence of erm(B) in S. pneumoniae was found to confer resistance to telithromycin, the first-generation ketolide, a semi-synthetic macrolide antibiotic, by allowing constitutive expression (Wolter et al., 2008).

\section{Macrolide Efflux}

Macrolide efflux in S. pneumoniae has been the most common cause of macrolide resistance in North America, the United Kingdom, and others (Table 1). Pneumococcal macrolide efflux is encoded by the mef(E)/mel operon and occurs through an as yet incompletely understood mechanism of macrolide binding and membrane targeting for efflux (Chancey et al., 2012). Macrolide resistance in S. pneumoniae requires both $m e f(\mathrm{E})$ and $m e l$. These genes are carried on the macrolide efflux genetic assembly (Mega) element and are expressed from a single promoter inducible by 14 - and 15 -membered macrolides (e.g., erythromycin, clarithromycin, and azithromycin; Gay and Stephens, 2001; Ambrose et al., 2005; Chancey et al., 2015b). Expression of $m e f(\mathrm{E})$ and $m e l$ is tightly controlled through transcriptional attenuation (Chancey et al., 2015b).

The first gene, mef(E) shares $90 \%$ sequence identity with mef(A) from Streptococcus pyogenes (Tait-Kamradt et al., 1997; Roberts et al., 1999). While mef(E) is most common, mef(A) is more common in Germany, Denmark, and Australia (Table 1). Another homolog, $m e f(\mathrm{I})$, also shares $91 \%$ identity with $m e f(\mathrm{~A})$, has been found in S. pneumoniae (Cochetti et al., 2005; Wierzbowski et al., 2005b) but is rarely found (Table 1). Most studies do not distinguish between $m e f(\mathrm{E})$ and $m e f(\mathrm{~A})$ and thus report only $m e f(\mathrm{E})$ or $m e f(\mathrm{~A})$ rather than $m e f(\mathrm{~A} / \mathrm{E})$, which is a more accurate description of the data. In S. pneumoniae, mef(E) encodes a 405 amino acid protein that belongs to the major facilitator superfamily, which utilizes proton motive force-driven efflux to expel molecules from cells (Tait-Kamradt et al., 1997). The second gene, $m e l$ (also known as $m s r(\mathrm{D})$ ) is a homolog of the $S$. aureus gene $\operatorname{mrs}(A)$ (Roberts et al., 1999), which encodes an ATP-binding cassette $(\mathrm{ABC})$ transporter protein but lacks typical hydrophobic, membrane-binding domains, and is predicted to interact with chromosomally encoded transmembrane complexes (Ambrose et al., 2005). $\operatorname{Mef}(\mathrm{E})$ and Mel have been shown to synergistically provide macrolide resistance and operate as a two-component efflux pump in $S$. pneumoniae (Ambrose et al., 2005; Zhang et al., 2016). A recent E. coli study suggests a physical interaction between $\operatorname{Mef}(\mathrm{E})$ and Mel and that Mel may bind macrolides and localize to the membrane (Nunez-Samudio and Chesneau, 2013). In $S$. pyogenes the presence of $m s r(\mathrm{D})$ alone was required for macrolide resistance (Zhang et al., 2016) and recent evidence suggests antibiotic resistance by ATP-binding cassette proteins may occur through ribosomal protection by displacing ribosome-bound macrolide molecules (Sharkey et al., 2016). Thus, the working 
TABLE 1 | Distribution of macrolide resistance genotypes by country.

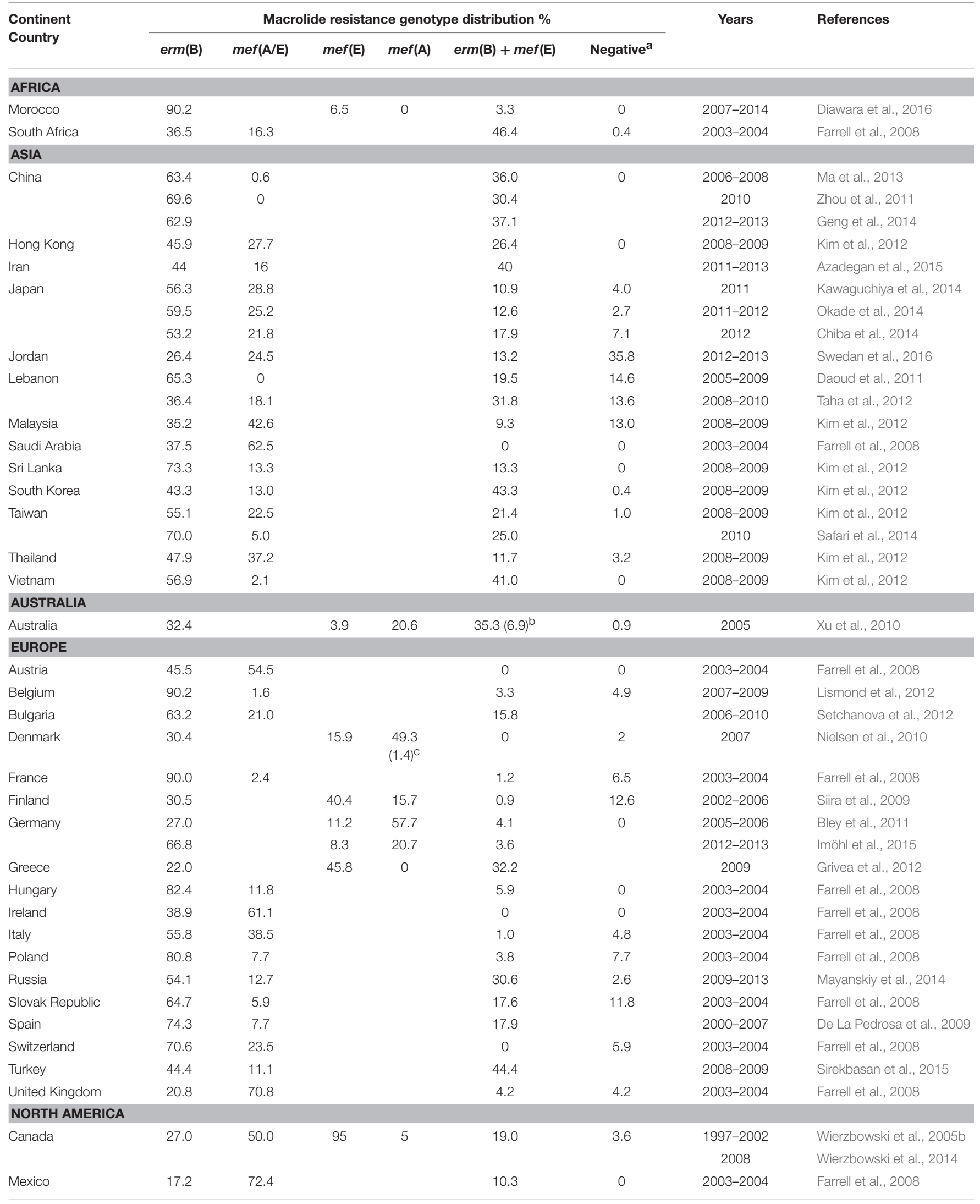


TABLE 1 | Continued

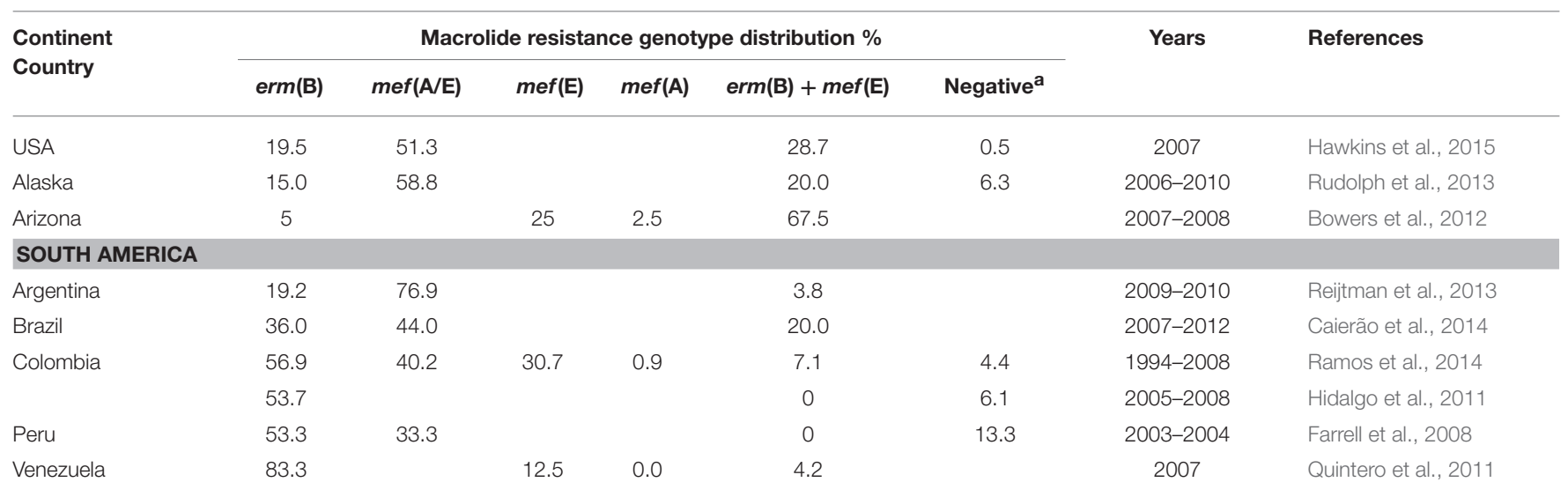

a $P C R$ negative for erm $(B), \operatorname{mef}(A / E), \operatorname{mef}(A)$, and mef(E). Some authors have determined these to be ribosomal mutations.

${ }^{b}$ Strains contain both erm $(B)$ and $\operatorname{mef}(A)$.

${ }^{c}$ Strains contain mef(l).

model for macrolide efflux in S. pneumoniae may be macrolide displacement from ribosomes by mel, which transfers macrolide molecules to $m e f(\mathrm{E})$ for efflux.

S. pneumoniae with mef(E)/mel have been shown to have an $M$ phenotype, which is resistant to 14 - and 15-membered macrolides but susceptible to lincosamides and streptogramin B (Tait-Kamradt et al., 1997). While $m e f(E) / m e l$-containing strains display low level resistance (MICs $1-8 \mu \mathrm{g} / \mathrm{ml}$ ) to erythromycin, macrolide induction increases expression of $m e f(\mathrm{E}) / \mathrm{mel}$ and results in increased levels of macrolide resistance (Wierzbowski et al., 2005a). Induction of $m e f(\mathrm{E}) / \mathrm{mel}$ by macrolides increases MICs to $\geq 16 \mu \mathrm{g} / \mathrm{ml}$ (Ambrose et al., 2005; Chancey et al., 2011). The presence of the two-component efflux pump encoded by mef(E)/mel also increases resistance to the human antimicrobial peptide LL-37 (Zähner et al., 2010). LL-37 also induces expression of the efflux pump (Zähner et al., 2010). These data may suggest the efflux pump is induced during nasopharyngeal colonization and primes the $m e f(\mathrm{E}) / m e l$-containing pneumococci to resist macrolide antibiotics.

\section{Ribosomal Mutations}

Point mutations in $23 \mathrm{~S}$ rRNA at or near the macrolide binding residue A2058 (E. coli ribosome) have resulted in high-level macrolide resistance (Vester and Douthwaite, 2001; Franceschi et al., 2004). Mutations of ribosomal proteins L4 and L22 confer macrolide resistance in pathogenic and nonpathogenic bacteria including pneumococci. L4 and L22 are ribosomal proteins with domains on the surface of the ribosome as well as tentacles that extend into the exit tunnel in proximity to the macrolide-binding site (Schuwirth et al., 2005). In E. coli, a Lys-63-Glu change in the $\mathrm{L} 4$ protein $(r p l D)$ as well as a triple amino acid deletion of Met-82, Lys-83, and Glu-84 from L22 ( $r p l V)$ confer resistance to macrolides (Wittmann et al., 1973; Chittum and Champney, 1994). A variety of additional L4 and L22 mutations have also been found to confer macrolide resistance (Zaman et al., 2007; Diner and Hayes, 2009). While the overall incidence is rare in
S. pneumoniae, L4 and L22 mutations have been shown to result in macrolide resistance (Franceschi et al., 2004).

\section{Dual Macrolide Resistance Genotype}

S. pneumoniae containing both $\operatorname{erm}(\mathrm{B})$ and $m e f(\mathrm{E}) / \mathrm{mel}$ were first reported in the late-1990s (Corso et al., 1998; Nishijima et al., 1999) and are now found worldwide (Farrell et al., 2008). The dual macrolide resistance genotype occurred in $12 \%$ of global isolates collected from 2003 to 2004, which is twice the frequency reported from 1999 to 2000 (Farrell et al., 2008). In $2004,18.4 \%$ of $S$. pneumoniae isolates from the US were found to have the dual erm(B) and $m e f(\mathrm{E}) / \mathrm{mel}$ genotype (Jenkins et al., 2008); in a recent study, up to $52 \%$ of macrolide-resistant isolates from Arizona were found to contain both macrolide resistance genes (Bowers et al., 2012). Tn2010 has been identified as the major composite mobile element that contains erm(B) and $m e f(\mathrm{E}) / \mathrm{mel}$ (Mega) (Del Grosso et al., 2006). Following introduction of the 7-valent pneumococcal conjugate vaccine (PCV-7) the "replacement" serotype 19A (ST320) with Tn2010 emerged (Del Grosso et al., 2007). ST320 is a multidrug resistant strain that appears to represent a "capsule switch" from serotype $19 \mathrm{~F}$ and is responsible for a global pandemic in the wake of PCV7 introduction (Moore et al., 2008; Li et al., 2011). The high-level and broader resistance conferred by erm(B) would predict that $m e f(\mathrm{E}) / \mathrm{mel}$ is functionally redundant in $\mathrm{erm}(\mathrm{B})$-containing $S$. pneumoniae.

\section{DISSEMINATION OF RESISTANCE DETERMINANTS}

\section{Macrolide Resistance Chromosomal Locations}

The mef(E)/mel-containing genetic element Mega is found in at least six distinct chromosomal sites within the pneumococcal genome (Chancey et al., 2015a), while mef(A) is found on Tn1207.1 (Xu et al., 2010). Mega insertion sites are distributed around the chromosome: (I) 
a phosphomethylpyrimidine kinase (TIGR4 SP_1598), (II) a DNA-3-methyladenine glycosylase (SP_0180), (III) a capsule biosynthesis gene (SP_0103), (IV) the RNA methyltransferase rumA (SP_1029) (Gay and Stephens, 2001), (V) orf6 of Tn916-like elements (Del Grosso et al., 2006), and (VI) a novel insertion into a $S$. suis homolog element found in S. pneumoniae (Chancey et al., 2015a). Due to genetic variations at insertion site IV, this class is subdivided: (IVa) Mega and ISSmi element insertion along with deletion of the $30.7 \mathrm{~kb}$ pneumococcal pathogenicity island-1 (PPI-1), and $(\mathrm{IVb})$ simple insertion of Mega into rumA with PPI-1 intact, and (IVc) same organization as IVa with a $S$. equi subspecies zooepidemicus-related integrative and conjugative element $(42 \mathrm{~kb})$ inserted upstream of Mega (Chancey et al., 2015a).

The Mega element lacks genes required for transposition (Gay and Stephens, 2001). Analysis of the Mega insertion sites revealed a putative target sequence of $5^{\prime}$-TTTCCNCAA$3^{\prime}$ about six base pairs upstream of the insertion and Tn916like coupling sequences (Chancey et al., 2015a). The genes required for Mega transposition may be present on other conjugative elements of the pneumococcal genome and in nonS. pneumoniae commensal organisms (Gay and Stephens, 2001; Chancey et al., 2015a). While Mega is infrequently transferred through transposition, once stabilized in the genome Mega is widely disseminated through horizontal DNA exchange and homologous recombination.

Tn916 is the prototype conjugative transposon that contains the tetracycline resistance gene tet $(\mathrm{M})$, and is found in many Gram-positive bacteria. Tn916 may incorporate additional antibiotic resistance determinants which comprise larger Tn916like composite elements (Roberts and Mullany, 2011). The history and molecular mechanisms of the Tn916 family are beyond the scope of this review, but have been explored previously (Roberts and Mullany, 2009). The most common Tn916-like elements in S. pneumoniae containing erythromycin resistance cassettes include Tn2009, Tn6002, and Tn2010 (Chancey et al., 2015a). Tn2009 is a Tn916-like element with Mega inserted into orf6 of Tn916 to provide macrolide resistance, the $M$ phenotype (Del Grosso et al., 2004). Tn6002 is also a Tn916-like element with macrolide resistance, with a $\mathrm{MLS}_{\mathrm{B}}$ phenotype due to the incorporation of an erm(B)containing element into orf20 of Tn916 (Brenciani et al., 2007). The erm(B) gene may also be incorporated into Tn916. Tn917, an erm(B)-containing transposon insertion into orf9 of Tn916 creates Tn3872 (Brenciani et al., 2007). S. pneumoniae with the dual macrolide resistance genotype most often contain Tn2010 or rarely the newly described element Tn2017 (Del Grosso et al., 2009). Tn2010 is a Tn916like element with Mega in orf6 and the $\operatorname{erm}(\mathrm{B})$ element in orf20 of Tn916 (Del Grosso et al., 2007). Tn2010 likely arose through the homologous recombination of Tn2009 with Tn6002 (Chancey et al., 2015a). A similar recombination event likely occurred with $\operatorname{Tn} 2009$ and Tn3872 to create Tn2017, which is a Tn916-like element with a Mega insertion in orf6 and Tn917 in orf9 of Tn916 (Del Grosso et al., 2009).

\section{Interspecies Exchange of Macrolide Resistance}

During the growth cycle, pneumococci develop a natural state of competence and can acquire DNA from the environment. A mechanism of DNA repair allows for integration of new DNA through homologous recombination (Straume et al., 2015). The human nasopharynx is the primary ecological niche for the pneumococcus during asymptomatic carriage (Simell et al., 2012), where S. pneumoniae has the opportunity to acquire DNA from other pneumococci and from commensal bacteria of the upper respiratory tract that may act as a reservoir for antibiotic resistance.

Other bacteria that reside in the human upper respiratory tract carry the macrolide resistance genes. Tn6002 is the most common erm(B)-containing mobile genetic element of $S$. pyogenes (Brenciani et al., 2007). A recent study found Mega, Tn2009, Tn6002, and Tn2010 in commensal viridans group streptococci isolated from the human oropharynx (Brenciani et al., 2014). In this study, S. mitis was the most commonly isolated streptococcal species with the macrolide resistance elements. Other Gram-positive bacteria have been shown to carry erm(B) and/or mef(E) (Luna et al., 1999; Seppälä et al., 2003; Santoro et al., 2014). The Tn2009 element has been found in commensal, Gram-negative Acinetobacter junii, and there is evidence of this Mega-containing transposon in other Gram-negative species including E. coli, Enterobacter cloacae, Klebsiella sp., Proteus sp., and Pseudomonas sp. (Ojo et al., 2006). Interspecies dissemination of mobile genetic elements containing antibiotic resistance cassettes appears common.

Asymptomatic pneumococcal carriage occurs in children and adults with rates in children ranging from $<15 \%$ to $>90 \%$ in developing countries (Shak et al., 2013). Carriage varies based on factors including geography and socioeconomic class (O'Brien and Nohynek, 2003; Simell et al., 2012). During nasopharyngeal carriage, $S$. pneumoniae forms biofilms that enhance natural transformation (Chao et al., 2014) and genetic exchange during co-colonization by two pneumococcal strains is efficient with transformation efficiencies up to $10^{-2}$ (Marks et al., 2012). This environment may have allowed for the dissemination of macrolide resistance determinants including the assembly and selection of the dual macrolide resistance elements, e.g., Tn2017 and the more common Tn2010 (discussed above).

\section{IMPACT OF PNEUMOCOCCAL CONJUGATE VACCINES ON MACROLIDE RESISTANCE}

Between 1994 and 1999, macrolide-resistant invasive pneumococcal disease (MR-IPD) rapidly emerged in the US largely due infections caused by isolates containing $m e f(\mathrm{E}) / \mathrm{mel}$ (Gay et al., 2000; Stephens et al., 2005). Introduction of PCV-7 in 2000 significantly reduced the incidence of MR-IPD in the US as the highest rates of macrolide resistance were present in PCV-7 vaccine serotypes (Stephens et al., 2005; Rudolph et al., 2013; Hawkins et al., 2015). Similar vaccine specific reductions were observed worldwide, which was observed in Germany through 
the reduction of mef(A)-containing serotype 14 (ST9) isolates (Bley et al., 2011; Imöhl et al., 2015). The incidence of MR-IPD from 2002 through 2009 stabilized while macrolide-resistant PCV-7 serotypes continued to decline; this decline was offset by the rapid emergence of macrolide-resistant serotypes not covered by PCV-7, specifically serotype 19A, ST320 (formerly CC271; Del Grosso et al., 2007; Bowers et al., 2012; Chancey et al., 2015a).

The incidence of MR-IPD caused by serotype 19A isolates with the dual macrolide resistance phenotype (both $\operatorname{erm}(\mathrm{B})$ and $m e f(\mathrm{E}) / \mathrm{mel}$ ) rapidly increased from 2003 through 2010 in the US and worldwide (Li et al., 2011; Quintero et al., 2011; Bowers et al., 2012; Sharma et al., 2013; Pan et al., 2015; Lyu et al., 2016). Selective pressure by PCV-7 and the continued high-level use of macrolides provided an opportunity for this 19A clone to expand worldwide. The introduction of PCV-13 in the later-2010, which contains serotype 19A, was successful in reducing carriage and IPD caused by vaccine serotypes including macrolideresistant serotype 19A isolates (Desai et al., 2015; Imöhl et al., 2015). Overall, pneumococcal conjugate vaccination has yielded sustained reductions in pneumococcal disease (Pilishvili et al., 2010). Despite challenges with serotype replacement, PCVs are an effective intervention in reducing the incidence of disease caused by macrolide-resistant pneumococcal serotypes contained in the vaccine. Continued expansion of pediatric pneumococcal vaccination into developing countries is predicted to greatly reduce the global burden of pneumococcal disease and antibiotic resistant pneumococci (Rodgers and Klugman, 2011).

\section{CONCLUSIONS}

Macrolide resistance rapidly emerged in $S$. pneumoniae in the early-1990s. The introduction and widespread use of semisynthetic macrolides including azithromycin and

\section{REFERENCES}

Ambrose, K. D., Nisbet, R., and Stephens, D. S. (2005). Macrolide efflux in Streptococcus pneumoniae is mediated by a dual efflux pump (mel and mef) and is erythromycin inducible. Antimicrob. Agents Chemother. 49, 4203-4209. doi: 10.1128/AAC.49.10.4203-4209.2005

Azadegan, A., Ahmadi, A., Lari, A. R., and Talebi, M. (2015). Detection of the efflux-mediated erythromycin resistance transposon in Streptococcus pneumoniae. Ann. Lab. Med. 35, 57-61. doi: 10.3343/alm.2015.35.1.57

Bergman, M., Huikko, S., Huovinen, P., Paakkari, P., and Seppälä, H. (2006). Macrolide and azithromycin use are linked to increased macrolide resistance in Streptococcus pneumoniae. Antimicrob. Agents Chemother. 50, 3646-3650. doi: 10.1128/AAC.00234-06

Bley, C., Van Der Linden, M., and Reinert, R. R. (2011). mef(A) is the predominant macrolide resistance determinant in Streptococcus pneumoniae and Streptococcus pyogenes in Germany. Int. J. Antimicrob. Agents 37, 425-431. doi: 10.1016/j.ijantimicag.2011.01.019

Bowers, J. R., Driebe, E. M., Nibecker, J. L., Wojack, B. R., Sarovich, D. S., Wong, A. $\mathrm{H}$., et al. (2012). Dominance of multidrug resistant CC271 clones in macrolideresistant Streptococcus pneumoniae in Arizona. BMC Microbiol. 12:12. doi: 10.1186/1471-2180-12-12

Brenciani, A., Bacciaglia, A., Vecchi, M., Vitali, L. A., Varaldo, P. E., and Giovanetti, E. (2007). Genetic elements carrying erm(B) in Streptococcus clarithromycin were important drivers of macrolide resistance in pneumococci. Macrolide resistance in $S$. pneumoniae is predominantly due to ribosomal methylation by the gene product encoded by $\operatorname{erm}(\mathrm{B})$ and macrolide efflux by a two-component efflux pump encoded by $m e f(\mathrm{E}) / \mathrm{mel}$ on the transformable genetic element Mega. Both of these macrolide resistance determinants are associated with larger composite elements (i.e., Tn6002 and Tn2009) and can be found on the same element. PCVs are effective in reducing macrolide resistance caused by vaccine serotypes and thus have been effective in the reduction of MR-IPD caused by vaccine strains. But "serotype replacement" has been an issue (e.g., 19A) and emergence of macrolide resistance in new serotypes is a concern. Continued research is needed to better understand the mechanism of macrolide efflux by $\mathrm{Mef}(\mathrm{E}) / \mathrm{Mel}$, the emergence of genetic elements containing both $\operatorname{erm}(\mathrm{B})$ and $m e f(\mathrm{E}) / \mathrm{mel}$, and to continue surveillance to monitor new changes in macrolide resistance in pneumococci.

\section{AUTHOR CONTRIBUTIONS}

MS wrote the paper and MS and DS developed and edited the paper.

\section{FUNDING}

The work was supported by Emory University (Ph. D. thesis).

\section{ACKNOWLEDGMENTS}

Thanks to Yih-Ling Tzeng and Sarah Satola for discussions of macrolide resistance and Valaria Cantos and Jeffery Collins for clinical insight. pyogenes and association with tet(M) tetracycline resistance gene. Antimicrob. Agents Chemother. 51, 1209-1216. doi: 10.1128/AAC.01484-06

Brenciani, A., Tiberi, E., Tili, E., Mingoia, M., Palmieri, C., Varaldo, P. E., et al. (2014). Genetic determinants and elements associated with antibiotic resistance in viridans group streptococci. J. Antimicrob. Chemother. 69, 1197-1204. doi: $10.1093 / \mathrm{jac} / \mathrm{dkt} 495$

Caierão, J., Hawkins, P., Sant'anna, F. H., Da Cunha, G. R., D’azevedo, P. A., Mcgee, L., et al. (2014). Serotypes and genotypes of invasive Streptococcus pneumoniae before and after PCV10 implementation in southern Brazil. PLoS ONE 9:e111129. doi: 10.1371/journal.pone.0111129

Camilli, R., Del Grosso, M., Iannelli, F., and Pantosti, A. (2008). New genetic element carrying the erythromycin resistance determinant erm(TR) in Streptococcus pneumoniae. Antimicrob. Agents Chemother. 52, 619-625. doi: 10.1128/AAC.01081-07

Chancey, S. T., Agrawal, S., Schroeder, M. R., Farley, M. M., Tettelin, H., and Stephens, D. S. (2015a). Composite mobile genetic elements disseminating macrolide resistance in Streptococcus pneumoniae. Front. Microbiol. 6:26. doi: 10.3389/fmicb.2015.00026

Chancey, S. T., Bai, X., Kumar, N., Drabek, E. F., Daugherty, S. C., Colon, T., et al. (2015b). Transcriptional attenuation controls macrolide inducible efflux and resistance in Streptococcus pneumoniae and in other Gram-positive bacteria containing mef/mel(msr(D)) elements. PLoS ONE 10:e0116254. doi: 10.1371/journal.pone.0116254 
Chancey, S. T., Zähner, D., and Stephens, D. S. (2012). Acquired inducible antimicrobial resistance in Gram-positive bacteria. Future Microbiol. 7, 959-978. doi: 10.2217/fmb.12.63

Chancey, S. T., Zhou, X., Zähner, D., and Stephens, D. S. (2011). Induction of efflux-mediated macrolide resistance in Streptococcus pneumoniae. Antimicrob. Agents Chemother. 55, 3413-3422. doi: 10.1128/AAC.00060-11

Chao, Y., Marks, L. R., Pettigrew, M. M., and Hakansson, A. P. (2014). Streptococcus pneumoniae biofilm formation and dispersion during colonization and disease. Front. Cell. Infect. Microbiol. 4:194. doi: 10.3389/fcimb.2014.00194

Chiba, N., Morozumi, M., Shouji, M., Wajima, T., Iwata, S., and Ubukata, K. (2014). Changes in capsule and drug resistance of Pneumococci after introduction of PCV7, Japan, 2010-2013. Emerging Infect. Dis. 20, 1132-1139. doi: $10.3201 /$ eid2007.131485

Chittum, H. S., and Champney, W. S. (1994). Ribosomal protein gene sequence changes in erythromycin-resistant mutants of Escherichia coli. J. Bacteriol. 176, 6192-6198.

Cochetti, I., Vecchi, M., Mingoia, M., Tili, E., Catania, M. R., Manzin, A., et al. (2005). Molecular characterization of pneumococci with efflux-mediated erythromycin resistance and identification of a novel mef gene subclass, mef(I). Antimicrob. Agents Chemother. 49, 4999-5006. doi: 10.1128/AAC.49.12.49995006.2005

Corso, A., Severina, E. P., Petruk, V. F., Mauriz, Y. R., and Tomasz, A. (1998). Molecular characterization of penicillin-resistant Streptococcus pneumoniae isolates causing respiratory disease in the United States. Microb. Drug Resist. 4, 325-337. doi: 10.1089/mdr.1998.4.325

Daoud, Z., Kourani, M., Saab, R., Nader, M. A., and Hajjar, M. (2011). Resistance of Streptococcus pneumoniae isolated from Lebanese patients between 2005 and 2009. Rev. Esp. Quimioter. 24, 84-90.

De La Pedrosa, E. G., Baquero, F., Loza, E., Nadal-Serrano, J. M., Fenoll, A., Del Campo, R., et al. (2009). High clonal diversity in erythromycin-resistant Streptococcus pneumoniae invasive isolates in Madrid, Spain (2000-07). J. Antimicrob. Chemother. 64, 1165-1169. doi: 10.1093/jac/dkp364

Del Grosso, M., Camilli, R., Iannelli, F., Pozzi, G., and Pantosti, A. (2006). The mef(E)-carrying genetic element (mega) of Streptococcus pneumoniae: insertion sites and association with other genetic elements. Antimicrob. Agents Chemother. 50, 3361-3366. doi: 10.1128/AAC.00277-06

Del Grosso, M., Camilli, R., Libisch, B., Füzi, M., and Pantosti, A. (2009). New composite genetic element of the $\mathrm{Tn} 916$ family with dual macrolide resistance genes in a Streptococcus pneumoniae isolate belonging to clonal complex 271. Antimicrob. Agents Chemother. 53, 1293-1294. doi: 10.1128/AAC.01066-08

Del Grosso, M., Northwood, J. G., Farrell, D. J., and Pantosti, A. (2007). The macrolide resistance genes $\operatorname{erm}(\mathrm{B})$ and $m e f(\mathrm{E})$ are carried by Tn2010 in dualgene Streptococcus pneumoniae isolates belonging to clonal complex CC271. Antimicrob. Agents Chemother. 51, 4184-4186. doi: 10.1128/AAC.00598-07

Del Grosso, M., Scotto D’abusco, A., Iannelli, F., Pozzi, G., and Pantosti, A. (2004). Tn2009, a Tn916-like element containing mef(E) in Streptococcus pneumoniae. Antimicrob. Agents Chemother. 48, 2037-2042. doi: 10.1128/AAC.48.6.20372042.2004

Desai, A. P., Sharma, D., Crispell, E. K., Baughman, W., Thomas, S., Tunali, A., et al. (2015). Decline in pneumococcal nasopharyngeal carriage of vaccine serotypes after the introduction of the 13-valent pneumococcal conjugate vaccine in children in Atlanta, Georgia. Pediatr. Infect. Dis. J. 34, 1168-1174. doi: 10.1097/INF.0000000000000849

Diawara, I., Zerouali, K., Katfy, K., Barguigua, A., Belabbes, H., Timinouni, M., et al. (2016). Phenotypic and genotypic characterization of Streptococcus pneumoniae resistant to macrolide in Casablanca, Morocco. Infect. Genet. Evol. 40, 200-204. doi: 10.1016/j.meegid.2016.03.003

Diner, E. J., and Hayes, C. S. (2009). Recombineering reveals a diverse collection of ribosomal proteins L4 and L22 that confer resistance to macrolide antibiotics. J. Mol. Biol. 386, 300-315. doi: 10.1016/j.jmb.2008.12.064

Farrell, D. J., Couturier, C., and Hryniewicz, W. (2008). Distribution and antibacterial susceptibility of macrolide resistance genotypes in Streptococcus pneumoniae: PROTEKT Year 5 (2003-2004). Int. J. Antimicrob. Agents 31, 245-249. doi: 10.1016/j.ijantimicag.2007.10.022

Franceschi, F., Kanyo, Z., Sherer, E. C., and Sutcliffe, J. (2004). Macrolide resistance from the ribosome perspective. Curr. Drug Targets Infect. Disord. 4, 177-191. doi: $10.2174 / 1568005043340740$
Gay, K., Baughman, W., Miller, Y., Jackson, D., Whitney, C. G., Schuchat, A., et al. (2000). The emergence of Streptococcus pneumoniae resistant to macrolide antimicrobial agents: a 6-year population-based assessment. J. Infect. Dis. 182, 1417-1424. doi: 10.1086/315853

Gay, K., and Stephens, D. S. (2001). Structure and dissemination of a chromosomal insertion element encoding macrolide efflux in Streptococcus pneumoniae. J. Infect. Dis. 184, 56-65. doi: 10.1086/321001

Geng, Q., Zhang, T., Ding, Y., Tao, Y., Lin, Y., Wang, Y., et al. (2014). Molecular characterization and antimicrobial susceptibility of Streptococcus pneumoniae isolated from children hospitalized with respiratory infections in Suzhou, China. PLoS ONE 9:e93752. doi: 10.1371/journal.pone.0093752

Grivea, I. N., Sourla, A., Ntokou, E., Chryssanthopoulou, D. C., Tsantouli, A. G., and Syrogiannopoulos, G. A. (2012). Macrolide resistance determinants among Streptococcus pneumoniae isolates from carriers in Central Greece. BMC Infect. Dis. 12:255. doi: 10.1186/1471-2334-12-255

Gupta, P., Sothiselvam, S., Vázquez-Laslop, N., and Mankin, A. S. (2013). Deregulation of translation due to post-transcriptional modification of rRNA explains why erm genes are inducible. Nat. Commun. 4:1984. doi: 10.1038/ncomms 2984

Hawkins, P. A., Chochua, S., Jackson, D., Beall, B., and Mcgee, L. (2015). Mobile elements and chromosomal changes associated with MLS resistance phenotypes of invasive pneumococci recovered in the United States. Microb. Drug Resist. 21, 121-129. doi: 10.1089/mdr.2014.0086

Hicks, L. A., Bartoces, M. G., Roberts, R. M., Suda, K. J., Hunkler, R. J., Taylor, T. H. Jr., et al. (2015). US outpatient antibiotic prescribing variation according to geography, patient population, and provider specialty in 2011. Clin. Infect. Dis. 60, 1308-1316. doi: 10.1093/cid/civ076

Hidalgo, M., Santos, C., Duarte, C., Castañeda, E., and Agudelo, C. I. (2011). [Increase in erythromycin-resistant Streptococcus pneumoniae in Colombia, 1994-2008]. Biomedica 31, 124-131. doi: 10.7705/biomedica.v31i1.343

Imöhl, M., Reinert, R. R., and Van Der Linden, M. (2015). Antibiotic susceptibility rates of invasive pneumococci before and after the introduction of pneumococcal conjugate vaccination in Germany. Int. J. Med. Microbiol. 305, 776-783. doi: 10.1016/j.ijmm.2015.08.031

Jenkins, S. G., Brown, S. D., and Farrell, D. J. (2008). Trends in antibacterial resistance among Streptococcus pneumoniae isolated in the USA: update from PROTEKT US Years 1-4. Ann. Clin. Microbiol. Antimicrob. 7:1. doi: 10.1186/1476-0711-7-1

Johnston, N. J., De Azavedo, J. C., Kellner, J. D., and Low, D. E. (1998). Prevalence and characterization of the mechanisms of macrolide, lincosamide, and streptogramin resistance in isolates of Streptococcus pneumoniae. Antimicrob. Agents Chemother. 42, 2425-2426.

Kannan, K., and Mankin, A. S. (2011). Macrolide antibiotics in the ribosome exit tunnel: species-specific binding and action. Ann. N. Y. Acad. Sci. 1241, 33-47. doi: 10.1111/j.1749-6632.2011.06315.x

Kawaguchiya, M., Urushibara, N., Ghosh, S., Kuwahara, O., Morimoto, S., Ito, M., et al. (2014). Serotype distribution and susceptibility to penicillin and erythromycin among noninvasive or colonization isolates of Streptococcus pneumoniae in northern Japan: a cross-sectional study in the pre-PCV7 routine immunization period. Microb. Drug Resist. 20, 456-465. doi: $10.1089 / \mathrm{mdr} .2013 .0196$

Keenan, J. D., Klugman, K. P., Mcgee, L., Vidal, J. E., Chochua, S., Hawkins, P., et al. (2015). Evidence for clonal expansion after antibiotic selection pressure: pneumococcal multilocus sequence types before and after mass azithromycin treatments. J. Infect. Dis. 211, 988-994. doi: 10.1093/infdis/jiu552

Kim, S. H., Song, J. H., Chung, D. R., Thamlikitkul, V., Yang, Y., Wang, H., et al. (2012). Changing trends in antimicrobial resistance and serotypes of Streptococcus pneumoniae isolates in Asian countries: an Asian Network for Surveillance of Resistant Pathogens (ANSORP) study. Antimicrob. Agents Chemother. 56, 1418-1426. doi: 10.1128/AAC.05658-11

Kirst, H. A. (2010). New macrolide, lincosaminide and streptogramin B antibiotics. Expert Opin. Ther. Pat. 20, 1343-1357. doi: 10.1517/13543776.2010. 505921

Klugman, K. P. (2002). Bacteriological evidence of antibiotic failure in pneumococcal lower respiratory tract infections. Eur. Respir. J. Suppl. 36, 3s-8s. doi: 10.1183/09031936.02.00400402

Li, Y., Tomita, H., Lv, Y., Liu, J., Xue, F., Zheng, B., et al. (2011). Molecular characterization of erm(B)- and mef(E)-mediated erythromycin-resistant 
Streptococcus pneumoniae in China and complete DNA sequence of Tn2010. J. Appl. Microbiol. 110, 254-265. doi: 10.1111/j.1365-2672.2010.04875.x

Lismond, A., Carbonnelle, S., Verhaegen, J., Schatt, P., De Bel, A., Jordens, P., et al. (2012). Antimicrobial susceptibility of Streptococcus pneumoniae isolates from vaccinated and non-vaccinated patients with a clinically confirmed diagnosis of community-acquired pneumonia in Belgium. Int. J. Antimicrob. Agents 39, 208-216. doi: 10.1016/j.ijantimicag.2011.11.011

Lonks, J. R., Garau, J., Gomez, L., Xercavins, M., Ochoa De Echagüen, A., Gareen, I. F., et al. (2002). Failure of macrolide antibiotic treatment in patients with bacteremia due to erythromycin-resistant Streptococcus pneumoniae. Clin. Infect. Dis. 35, 556-564. doi: 10.1086/341978

Luna, V. A., Coates, P., Eady, E. A., Cove, J. H., Nguyen, T. T., and Roberts, M. C. (1999). A variety of gram-positive bacteria carry mobile mef genes. J. Antimicrob. Chemother. 44, 19-25. doi: 10.1093/jac/44.1.19

Lyu, S., Yao, K.-H., Dong, F., Xu, B.-P., Liu, G., Wang, Q., et al. (2016). Vaccine serotypes of Streptococcus pneumoniae with high-level antibiotic resistance isolated more frequently seven years after the licensure of PCV7 in Beijing. Pediatr. Infect. Dis. J. 35, 316-321. doi: 10.1097/INF.0000000000001000

Ma, X., Yao, K.-H., Xie, G.-L., Zheng, Y.-J., Wang, C.-Q., Shang, Y. X., et al. (2013). Characterization of erythromycin-resistant Streptococcus pneumoniae isolates causing invasive diseases in Chinese children. Chin. Med. J. 126, 1522-1527. doi: 10.3760/cma.j.issn.0366-6999.20122185

Malhotra-Kumar, S., Lammens, C., Coenen, S., Van Herck, K., and Goossens, H. (2007). Effect of azithromycin and clarithromycin therapy on pharyngeal carriage of macrolide-resistant streptococci in healthy volunteers: a randomised, double-blind, placebo-controlled study. Lancet 369, 482-490. doi: 10.1016/S0140-6736(07)60235-9

Marks, L. R., Reddinger, R. M., and Hakansson, A. P. (2012). High levels of genetic recombination during nasopharyngeal carriage and biofilm formation in Streptococcus pneumoniae. MBio 3:e00200-12. doi: 10.1128/mBio.00200-12

Mayanskiy, N., Alyabieva, N., Ponomarenko, O., Lazareva, A., Katosova, L., Ivanenko, A., et al. (2014). Serotypes and antibiotic resistance of non-invasive Streptococcus pneumoniae circulating in pediatric hospitals in Moscow, Russia. Int. J. Infect. Dis. 20, 58-62. doi: 10.1016/j.ijid.2013.11.005

McGuire, J. M., Bunch, R. L., Anderson, R. C., Boaz, H. E., Flynn, E. H., and Powell, H. M. (1952). 'Ilotycin', a new antibiotic. Antibiot. Chemother. 2, 281-283.

Min, Y. H., Kwon, A. R., Yoon, E. J., Shim, M. J., and Choi, E. C. (2008). Translational attenuation and mRNA stabilization as mechanisms of erm(B) induction by erythromycin. Antimicrob. Agents Chemother. 52, 1782-1789. doi: 10.1128/AAC.01376-07

Moore, M. R., Gertz, R. E. Jr., Woodbury, R. L., Barkocy-Gallagher, G. A., Schaffner, W., Lexau, C., et al. (2008). Population snapshot of emergent Streptococcus pneumoniae serotype 19A in the United States, 2005. J. Infect. Dis. 197, 1016-1027. doi: 10.1086/528996

Nielsen, K. L., Hammerum, A. M., Lambertsen, L. M., Lester, C. H., Arpi, M., Knudsen, J. D., et al. (2010). Characterization and transfer studies of macrolide resistance genes in Streptococcus pneumoniae from Denmark. Scand. J. Infect. Dis. 42, 586-593. doi: 10.3109/00365541003754451

Nishijima, T., Saito, Y., Aoki, A., Toriya, M., Toyonaga, Y., and Fujii, R. (1999). Distribution of $m e f E$ and ermB genes in macrolide-resistant strains of Streptococcus pneumoniae and their variable susceptibility to various antibiotics. J. Antimicrob. Chemother. 43, 637-643. doi: 10.1093/jac/43.5.637

Nunez-Samudio, V., and Chesneau, O. (2013). Functional interplay between the ATP binding cassette Msr(D) protein and the membrane facilitator superfamily Mef(E) transporter for macrolide resistance in Escherichia coli. Res. Microbiol. 164, 226-235. doi: 10.1016/j.resmic.2012.12.003

O’Brien, K. L., and Nohynek, H. (2003). Report from a WHO Working Group: standard method for detecting upper respiratory carriage of Streptococcus pneumoniae. Pediatr. Infect. Dis. J. 22, e1-e11. doi: 10.1097/01.inf.0000049347.42983.77

Ojo, K. K., Ruehlen, N. L., Close, N. S., Luis, H., Bernardo, M., Leitao, J., et al. (2006). The presence of a conjugative Gram-positive Tn2009 in Gramnegative commensal bacteria. J. Antimicrob. Chemother. 57, 1065-1069. doi: $10.1093 / \mathrm{jac} / \mathrm{dkl} 094$

Okade, H., Funatsu, T., Eto, M., Furuya, Y., Mizunaga, S., Nomura, N., et al. (2014). Impact of the pneumococcal conjugate vaccine on serotype distribution and susceptibility trends of pediatric non-invasive Streptococcus pneumoniae isolates in Tokai, Japan over a 5-year period. J. Infect. Chemother. 20, 423-428. doi: 10.1016/j.jiac.2014.03.010

Pan, F., Han, L., Huang, W., Tang, J., Xiao, S., Wang, C., et al. (2015). Serotype distribution, antimicrobial susceptibility, and molecular epidemiology of Streptococcus pneumoniae isolated from Children in Shanghai, China. PLoS ONE 10:e0142892. doi: 10.1371/journal.pone.0142892

Pilishvili, T., Lexau, C., Farley, M. M., Hadler, J., Harrison, L. H., Bennett, N. M., et al. (2010). Sustained reductions in invasive pneumococcal disease in the era of conjugate vaccine. J. Infect. Dis. 201, 32-41. doi: 10.1086/648593

Pokkunuri, I., and Champney, W. S. (2007). Characteristics of a 50 S ribosomal subunit precursor particle as a substrate for ermE methyltransferase activity and erythromycin binding in Staphylococcus aureus. RNA Biol. 4, 147-153. doi: 10.4161/rna.4.3.5346

Quintero, B., Araque, M., Van Der Gaast-De Jongh, C., and Hermans, P. W. (2011). Genetic diversity of Tn916-related transposons among drug-resistant Streptococcus pneumoniae isolates colonizing healthy children in Venezuela. Antimicrob. Agents Chemother. 55, 4930-4932. doi: 10.1128/AAC.00242-11

Ramos, V., Duarte, C., Díaz, A., and Moreno, J. (2014). [Mobile genetic elements associated with erythromycin-resistant isolates of Streptococcus pneumoniae in Colombia]. Biomedica 34(Suppl. 1), 209-216. doi: 10.1590/S0120-41572014000500023

Reijtman, V., Gagetti, P., Faccone, D., Fossati, S., Sommerfleck, P., Hernández, C., et al. (2013). Macrolide resistance in Streptococcus pneumoniae isolated from Argentinian pediatric patients suffering from acute otitis media. Rev. Argent. Microbiol. 45, 262-266. doi: 10.1016/s0325-7541(13)70034-8

Roberts, A. P., and Mullany, P. (2009). A modular master on the move: the Tn916 family of mobile genetic elements. Trends Microbiol. 17, 251-258. doi: 10.1016/j.tim.2009.03.002

Roberts, A. P., and Mullany, P. (2011). Tn916-like genetic elements: a diverse group of modular mobile elements conferring antibiotic resistance. FEMS Microbiol. Rev. 35, 856-871. doi: 10.1111/j.1574-6976.2011.00283.x

Roberts, M. C., Sutcliffe, J., Courvalin, P., Jensen, L. B., Rood, J., and Seppala, H. (1999). Nomenclature for macrolide and macrolide-lincosamidestreptogramin B resistance determinants. Antimicrob. Agents Chemother. 43, 2823-2830.

Rodgers, G. L., and Klugman, K. P. (2011). The future of pneumococcal disease prevention. Vaccine 29S, C43-C48. doi: 10.1016/j.vaccine.2011.07.047

Rudolph, K., Bulkow, L., Bruce, M., Zulz, T., Reasonover, A., Harker-Jones, M., et al. (2013). Molecular resistance mechanisms of macrolide-resistant invasive Streptococcus pneumoniae isolates from Alaska, 1986 to 2010. Antimicrob. Agents Chemother. 57, 5415-5422. doi: 10.1128/AAC.00319-13

Safari, D., Kuo, L.-C., Huang, Y.-T., Liao, C.-H., Sheng, W.-H., and Hsueh, P.-R. (2014). Increase in the rate of azithromycin-resistant Streptococcus pneumoniae isolates carrying the $\operatorname{erm}(\mathrm{B})$ and $\operatorname{mef}(\mathrm{A})$ genes in Taiwan, 2006-2010. BMC Infect. Dis. 14:704. doi: 10.1186/s12879-014-0704-Z

Santoro, F., Vianna, M. E., and Roberts, A. P. (2014). Variation on a theme; an overview of the $\operatorname{Tn} 916 / \operatorname{Tn} 1545$ family of mobile genetic elements in the oral and nasopharyngeal streptococci. Front. Microbiol. 5:535. doi: 10.3389/fmicb.2014.00535

Schentag, J. J., Klugman, K. P., Yu, V. L., Adelman, M. H., Wilton, G. J., Chiou, C. C., et al. (2007). Streptococcus pneumoniae bacteraemia: pharmacodynamic correlations with outcome and macrolide resistance-a controlled study. Int. J. Antimicrob. Agents 30, 264-269. doi: 10.1016/j.ijantimicag.2007. 04.013

Schuwirth, B. S., Borovinskaya, M. A., Hau, C. W., Zhang, W., Vila-Sanjurjo, A., Holton, J. M., et al. (2005). Structures of the bacterial ribosome at $3.5 \mathrm{~A}$ resolution. Science 310, 827-834. doi: 10.1126/science.1117230

Seiple, I. B., Zhang, Z., Jakubec, P., Langlois-Mercier, A., Wright, P. M., Hog, D. T., et al. (2016). A platform for the discovery of new macrolide antibiotics. Nature 533, 338-345. doi: 10.1038/nature17967

Seppälä, H., Haanperä, M., Al-Juhaish, M., Järvinen, H., Jalava, J., and Huovinen, P. (2003). Antimicrobial susceptibility patterns and macrolide resistance genes of viridans group streptococci from normal flora. J. Antimicrob. Chemother. 52, 636-644. doi: 10.1093/jac/dkg423

Setchanova, L. P., Alexandrova, A., Mitov, I., Nashev, D., and Kantardjiev, T. (2012). Serotype distribution and antimicrobial resistance of invasive Streptococcus pneumoniae isolates in Bulgaria before the introduction 
of pneumococcal conjugate vaccine. J. Chemother. 24, 12-17. doi: 10.1179/1120009X12Z.0000000004

Shak, J. R., Vidal, J. E., and Klugman, K. P. (2013). Influence of bacterial interactions on pneumococcal colonization of the nasopharynx. Trends Microbiol. 21, 129-135. doi: 10.1016/j.tim.2012.11.005

Sharkey, L. K., Edwards, T. A., and O'neill, A. J. (2016). ABC-F proteins mediate antibiotic resistance through ribosomal protection. MBio 7:e01975. doi: 10.1128/mBio.01975-15

Sharma, D., Baughman, W., Holst, A., Thomas, S., Jackson, D., Da Gloria Carvalho, M., et al. (2013). Pneumococcal carriage and invasive disease in children before introduction of the 13-valent conjugate vaccine: comparison with the era before 7-valent conjugate vaccine. Pediatr. Infect. Dis. J. 32, e45-e53. doi: 10.1097/inf.0b013e3182788fdd

Siira, L., Rantala, M., Jalava, J., Hakanen, A. J., Huovinen, P., Kaijalainen, T., et al. (2009). Temporal trends of antimicrobial resistance and clonality of invasive Streptococcus pneumoniae isolates in Finland, 2002 to 2006. Antimicrob. Agents Chemother. 53, 2066-2073. doi: 10.1128/AAC.01464-08

Simell, B., Auranen, K., Käyhty, H., Goldblatt, D., Dagan, R., and O'brien, K. L. (2012). The fundamental link between pneumococcal carriage and disease. Expert Rev. Vaccines 11, 841-855. doi: 10.1586/erv.12.53

Sirekbasan, L., Gönüllü, N., Sirekbasan, S., Kuskucu, M., and Midilli, K. (2015). Phenotypes and genotypes of macrolide-resistant Streptococcus pneumoniae. Balkan Med. J. 32, 84-88. doi: 10.5152/balkanmedj.2015.15169

Skinner, R., Cundliffe, E., and Schmidt, F. J. (1983). Site of action of a ribosomal RNA methylase responsible for resistance to erythromycin and other antibiotics. J. Biol. Chem. 258, 12702-12706.

Stephens, D. S., Zughaier, S. M., Whitney, C. G., Baughman, W. S., Barker, L., Gay, K., et al. (2005). Incidence of macrolide resistance in Streptococcus pneumoniae after introduction of the pneumococcal conjugate vaccine: population-based assessment. Lancet 365, 855-863. doi: 10.1016/S0140-6736(05)71043-6

Straume, D., Stamsås, G. A., and Håvarstein, L. S. (2015). Natural transformation and genome evolution in Streptococcus pneumoniae. Infect. Genet. Evol. 33, 371-380. doi: 10.1016/j.meegid.2014.10.020

Swedan, S. F., Hayajneh, W. A., and Bshara, G. N. (2016). Genotyping and serotyping of macrolide and multidrug resistant Streptococcus pneumoniae isolated from carrier children. Indian J. Med. Microbiol. 34, 159-165. doi: $10.4103 / 0255-0857.176840$

Syrogiannopoulos, G. A., Grivea, I. N., Tait-Kamradt, A., Katopodis, G. D., Beratis, N. G., Sutcliffe, J., et al. (2001). Identification of an erm(A) erythromycin resistance methylase gene in Streptococcus pneumoniae isolated in Greece. Antimicrob. Agents Chemother. 45, 342-344. doi: 10.1128/AAC.45.1.342344.2001

Taha, N., Araj, G. F., Wakim, R. H., Kanj, S. S., Kanafani, Z. A., Sabra, A., et al. (2012). Genotypes and serotype distribution of macrolide resistant invasive and non-invasive Streptococcus pneumoniae isolates from Lebanon. Ann. Clin. Microbiol. Antimicrob. 11:2. doi: 10.1186/1476-0711-11-2

Tait-Kamradt, A., Clancy, J., Cronan, M., Dib-Haji, F., Wondrack, L., Yuan, W., et al. (1997). mefE is necessary for the erythromycin-resistant $M$ phenotype in Streptococcus pneumoniae. Antimicrob. Agents Chemother. 41, 2251-2255.

Vester, B., and Douthwaite, S. (2001). Macrolide resistance conferred by base substitutions in 23S rRNA. Antimicrob. Agents Chemother. 45, 1-12. doi: 10.1128/AAC.45.1.1-12.2001

Walker, C. L., Rudan, I., Liu, L., Nair, H., Theodoratou, E., Bhutta, Z. A., et al. (2013). Global burden of childhood pneumonia and diarrhoea. Lancet 381, 1405-1416. doi: 10.1016/S0140-6736(13)60222-6

Weisblum, B. (1995a). Erythromycin resistance by ribosome modification. Antimicrob. Agents Chemother. 39, 577-585.

Weisblum, B. (1995b). Insights into erythromycin action from studies of its activity as inducer of resistance. Antimicrob. Agents Chemother. 39, 797-805.
Wierzbowski, A. K., Boyd, D., Mulvey, M., Hoban, D. J., and Zhanel, G. G. (2005a). Expression of the mef(E) gene encoding the macrolide efflux pump protein increases in Streptococcus pneumoniae with increasing resistance to macrolides. Antimicrob. Agents Chemother. 49, 4635-4640. doi: 10.1128/AAC.49.11.46354640.2005

Wierzbowski, A. K., Karlowsky, J. A., Adam, H. J., Nichol, K. A., Hoban, D. J., Zhanel, G. G., et al. (2014). Evolution and molecular characterization of macrolide-resistant Streptococcus pneumoniae in Canada between 1998 and 2008. J. Antimicrob. Chemother. 69, 59-66. doi: 10.1093/jac/ $\mathrm{dkt} 332$

Wierzbowski, A. K., Swedlo, D., Boyd, D., Mulvey, M., Nichol, K. A., Hoban, D. J., et al. (2005b). Molecular epidemiology and prevalence of macrolide efflux genes mef(A) and mef(E) in Streptococcus pneumoniae obtained in Canada from 1997 to 2002. Antimicrob. Agents Chemother. 49, 1257-1261. doi: 10.1128/AAC.49.3.1257-1261.2005

Wittmann, H. G., Stöfler, G., Apirion, D., Rosen, L., Tanaka, K., Tamaki, M., et al. (1973). Biochemical and genetic studies on two different types of erythromycin resistant mutants of Escherichia coli with altered ribosomal proteins. Mol. Gen. Genet. 127, 175-189. doi: 10.1007/BF00333665

Wolter, N., Smith, A. M., Farrell, D. J., Northwood, J. B., Douthwaite, S., and Klugman, K. P. (2008). Telithromycin resistance in Streptococcus pneumoniae is conferred by a deletion in the leader sequence of erm(B) that increases rRNA methylation. Antimicrob. Agents Chemother. 52, 435-440. doi: 10.1128/AAC.01074-07

Xiao, Y., Wei, Z., Shen, P., Ji, J., Sun, Z., Yu, H., et al. (2015). Bacterial-resistance among outpatients of county hospitals in China: significant geographic distinctions and minor differences between central cities. Microbes Infect. 17, 417-425. doi: 10.1016/j.micinf.2015.02.001

Xu, X., Cai, L., Xiao, M., Kong, F., Oftadeh, S., Zhou, F., et al. (2010). Distribution of serotypes, genotypes, and resistance determinants among macrolideresistant Streptococcus pneumoniae isolates. Antimicrob. Agents Chemother. 54, 1152-1159. doi: 10.1128/AAC.01268-09

Zähner, D., Zhou, X., Chancey, S. T., Pohl, J., Shafer, W. M., and Stephens, D. S. (2010). Human antimicrobial peptide LL-37 induces MefE/Mel-mediated macrolide resistance in Streptococcus pneumoniae. Antimicrob. Agents Chemother. 54, 3516-3519. doi: 10.1128/AAC. 01756-09

Zaman, S., Fitzpatrick, M., Lindahl, L., and Zengel, J. (2007). Novel mutations in ribosomal proteins L4 and L22 that confer erythromycin resistance in Escherichia coli. Mol. Microbiol. 66, 1039-1050. doi: 10.1111/j.13652958.2007.05975.x

Zhang, Y., Tatsuno, I., Okada, R., Hata, N., Matsumoto, M., Isaka, M., et al. (2016). Predominant role of $m s r(\mathrm{D})$ over $m e f(\mathrm{~A})$ in macrolide resistance in Streptococcus pyogenes. Microbiology 162, 46-52. doi: 10.1099/mic.0.000206

Zhou, L., Yu, S.-J., Gao, W., Yao, K.-H., Shen, A. D., and Yang, Y.-H. (2011). Serotype distribution and antibiotic resistance of 140 pneumococcal isolates from pediatric patients with upper respiratory infections in Beijing, 2010. Vaccine 29, 7704-7710. doi: 10.1016/j.vaccine.2011.07.137

Conflict of Interest Statement: The authors declare that the research was conducted in the absence of any commercial or financial relationships that could be construed as a potential conflict of interest.

Copyright $\odot 2016$ Schroeder and Stephens. This is an open-access article distributed under the terms of the Creative Commons Attribution License (CC BY). The use, distribution or reproduction in other forums is permitted, provided the original author(s) or licensor are credited and that the original publication in this journal is cited, in accordance with accepted academic practice. No use, distribution or reproduction is permitted which does not comply with these terms. 